\title{
Organisational learning via groupware: a path to discovery or disaster?
}

\section{Neel Chauhan}

The Wharton School, University of Pennsylvania, 3730 Walnut Street, Philadelphia, PA, USA 19104.6340

Fax: 2158980120 E-mail: neel.chauhan.wg05@wharton.upenn.edu

\section{Nick Bontis*}

DeGroote School of Business,

McMaster University, 1280 Main Street West,

MGD No. 207, Hamilton, Ontario Canada L8S 4M4

Fax: $9055218995 \quad$ E-mail: nbontis@mcmaster.ca

${ }^{*}$ Corresponding author

\begin{abstract}
In order for organisations to keep up with the onslaught of challenges inherent in the knowledge era, they must continuously learn. From a normative perspective, groupware technologies facilitate organisational learning by providing a means of disseminating and codifying organisational knowledge. However, in practice, the potential learning benefits of groupware are rarely achieved. This paper aims to contribute to the fields of organisational learning, innovation and information systems by examining possible reasons for groupware failures, which lead to lost potential learning benefits and thus unsustainable advantage.
\end{abstract}

Keywords: groupware; organisational learning; intellectual capital; push-pull theory.

Reference to this paper should be made as follows: Chauhan, N. and Bontis, N. (2004) 'Organisational learning via groupware: a path to discovery or disaster?', Int. J. Technology Management, Vol. 27, Nos. 6/7, pp.591-610.

Biographical notes: Neel Chauhan is an MBA candidate at the Wharton School. Formerly he was a Senior Analyst at Loyalty Management in London, United Kingdom. He has worked on a variety of new economy projects ranging from e-business strategy to start-up business planning. Prior to Loyalty, Neel worked at Andersen as a Senior Analyst. He has extensive experience in the entertainment industry where he crafted and executed marketing plans for companies such as Calvin Klein, Guess and Warner Bros. Neel has published a number of papers in Business Sense Magazine. He holds a Master of Science degree from the London School of Economics and a Bachelor of Commerce degree from Ryerson Polytechnic University.

Dr. Bontis is currently Associate Professor of Strategic Management at the Michael G. DeGroote School of Business, McMaster University. He is also Director of the Institute for Intellectual Capital Research Inc., Chief Knowledge Officer of Knexa Solutions - the world's first knowledge exchange auction, and Associate Editor of the Journal of Intellectual Capital. Dr. Bontis completed his Doctoral Education at the Ivey School of Business, University of Western Ontario. Professor Bontis has won international acclaim for many of 
his academic research papers, book chapters and business management cases. Tom Stewart, Editor of Harvard Business Review, recognises him as "one of the world's real intellectual capital experts".

\section{Introduction}

Bontis [1] and his colleagues note that today's fierce competitive landscape coupled with the advent of the knowledge era forces organisations to learn efficiently and effectively in order to survive [2-5]. Organisational learning also enables companies to build capabilities, and intellectual capital, which can provide the firm with the ability to manage intangible resources for a sustainable competitive advantage [6-14]. Within this setting, the field of organisational learning has thrived. The study of organisational learning $(\mathrm{OL})$ is important because it provides academics and professionals with more insight into the system that enables organisations to generate knowledge and adapt to change. Nonaka [15] summarises the essence and importance of knowledge generation, which is a critical component of OL:
"When markets shift, technologies proliferate, competitors multiply, and products become obsolete almost overnight, successful companies are those that consistently create new knowledge, disseminate it widely throughout the organization, and quickly embody it in new technologies and products. These activities define the 'knowledge-creating' company whose sole business is continuous innovation." $[15, \mathrm{p} .96]$

Organisational learning is important because, among other things, it enables companies to build capabilities and intellectual resources, which can provide the firm with a sustainable competitive advantage. It is now common for computer applications to offer much more intangible, strategic benefits such as supporting OL [16]. A group of applications that provide such benefits are groupware. From a normative perspective, groupware applications facilitate organisational learning by supporting collaboration amongst organisational group members. However, in practice, the full learning benefits of using groupware are rarely achieved because these applications are often resisted [17-19].

This study takes some initial steps to explore possible reasons for groupware implementation failures, which prevent organisations from gleaning full learning benefits from such applications. We draw on the push-pull theory of implementation, from the disciplines of engineering and marketing, in an attempt to gain insight into reasons for the lack of success with these collaborative applications. Specifically, we argue that groupware applications that have been introduced as a result of a need (a pull strategy) are more successful. We draw on findings from research conducted at InfoProv, a major global information provider. The following two sections review the organisational learning and groupware literatures, respectively.

\section{Organisational learning literature review}

Fiol and Lyles [20, p.804] define organisational learning as “ $\ldots$ the process of improving actions through better knowledge and understanding". In the words of Garvin 


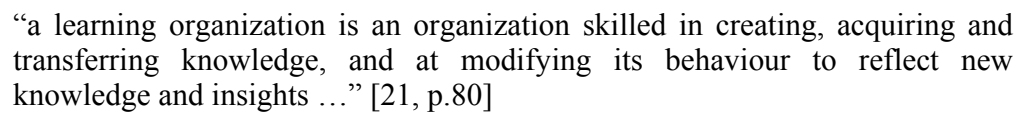

While some elements of the definitions of learning are similar, they tend to differ based on their assumptions of levels of analysis, cognition and the relation of learning and performance [2]. Neilson [18, p.2] defines learning as "leveraging the collective intellectual material of an organization to produce a higher level organizational asset ..." ". Argyris [22] defines OL as a process of detecting and correcting error. Another way to understand OL is as a level of learning that is something greater than group or individual levels of learning. This definition implies that OL is something more than the sum of the learning of the individuals that it is made up of [4]. Most of these definitions imply that OL is a process, as opposed to a programme, which involves some sort of change in behaviour. Huber [23] recognises that learning does not necessarily result in changed behaviour as some academics have suggested [21,24,25]. This is evident in his definition of learning which states that an entity learns if, through its processing of information, the range of its potential behaviours is changed [23]. For the purposes of this paper, we adopt Fiol and Lyles' aforementioned classic definition, while recognising the differences between organisational, group and individual levels of learning as per Bontis [1] and Bontis et al. [2].

There are several key conceptualisations within the OL literature that serve as a platform for gaining a better understanding of how groupware applications can support learning.

\subsection{Cognition}

A number of learning theorists have pointed out that there are two main views of learning, which are not necessarily mutually exclusive. These have been identified in the literature as cognitive and behavioural views [4,20,21,23,24]. Crossan et al. [4] make the distinction between these two views eloquently:

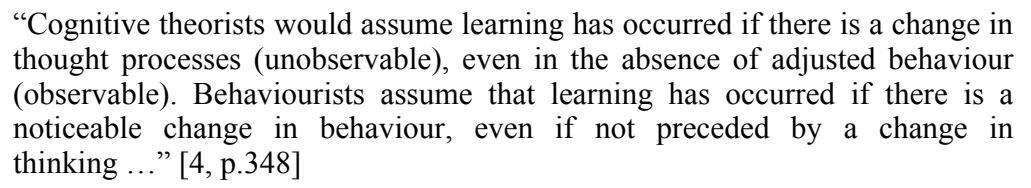

Beyond changes in behaviour, it has been argued that organisational learning should result in some sort of improvement in performance [20,21,23-25]. However, there is no evidence to suggest that there is indeed a connection between learning and performance [4]. One problem with making a distinction between cognitive and behavioural learning is that it assumes that it is possible to recognise or measure behavioural changes that result from learning.

\subsection{Double loop learning theory}

Argyris [22] argues that organisational learning is a process of detecting and correcting errors. He identifies two types of learning, which he calls single loop and double loop. Single loop learning involves a simple change. It can be seen as a simple error detection and correction. Argyris [22] gives the example of a thermostat turning on to adjust the 
room temperature to a predetermined heat. Double loop learning is more involved than single loop learning, in that it can involve a change in the organisations methods or policies. Argyris [22] gives the example of questioning the appropriateness of the current method of heating employed by an organisation. A double loop approach to a heating 'error' would be to question whether or not a heat pump could do a better job than the existing furnace. Concepts similar to single and double loop learning are present in the literature. For example, Fiol and Lyles [20] refer to single loop learning as lower-level learning and others refer to it as operational learning. Argyris' [22] theory is lacking in a sense that it does not provide us with any insight into when to use each of the type of learning. Neilson [18] also points out that Argyris' theories do not provide practitioners with any guidelines to identify learning problems or errors.

\subsection{Modes of learning}

Miller [26] identified and defined different modes of organisational learning. Learning takes place at different levels within these modes, which are analytical, synthetic, experimental, interactive, structural, and institutional. Analytical learning is characterised by informational gathering, rational analysis, selection of an 'optimal' alternative, and evaluation of performance. Synthesis usually involves a creative individual looking at a situation, often by examining texts, in a different way. The result of this different view can be new goals, procedures or decisions. Experimental learning involves performing experiments and monitoring the results. Interactive learning involves learning by doing, but in a less systematic way than with experimental learning. Structural learning refers to learning from the routines of an organisation. These structured routines are codified lessons from previous analytical learning. Finally, Miller [26, p.495] defines Institutional learning as " ... an emergent inductive process by which organisations assimilate values, ideologies and practices ...". Miller [26] points out that learning at this level may involve indoctrination, socialisation, and coercion and, as a result, does not allow much room for voluntarism.

\subsection{Constructs of learning}

Huber [23] breaks the broad term of organisational learning down into four constructs, namely, knowledge acquisition, information distribution, information interpretation and organisational memory. Knowledge acquisition is defined as the process in which knowledge is acquired or obtained. Information distribution is the process by which information is shared. Information interpretation involves attempting to develop one or more common interpretations of distributed knowledge. Organisational memory is defined as knowledge that is stored for use.

\subsection{Measurement}

A number of authors have stressed the importance of measuring learning [1-4,8,11,27]. Garvin [21] stressed that it is necessary to use a number of factors to measure learning benefits above and beyond the commonly used measures of price or cost improvements. Other factors that should be measured include quality, delivery and new product introductions [21]. However, while measuring learning is important, it is easier said than done. 


\subsection{Order from chaos}

Nonaka [28] argues that organisations that stay in a steady state (i.e. do not change) do not learn. He describes how organisations can generate knowledge by continually being in a state of non-equilibrium, which means identifying and considering a variety of options (never having a fixed course of action or way of organising). This opens up a company's eyes to new points of view, which could be better, more profitable, ways of organising [28].

\subsection{Bounded rationality}

Simon [29] recognises the importance of understanding the intricacies of OL. In particular, he stresses understanding, not just knowing or learning. Simon [29] notes that knowledge is stored in two places, people's heads or in files (data banks). As a result, maintaining knowledge in organisations depends on codification and dissemination of knowledge of individuals. The knowledge that an organisation has, at any given time, can be looked at like its memory and has been described by Bontis [1,6,27] as stocks of knowledge.

Many of the aforementioned conceptualisations have provided normative sequential models of organisational learning. It is unlikely that learning takes place in such a linear fashion [25]. In fact, most learning in organisations likely takes place in a more natural serendipitous fashion. This is part of a broader problem of oversimplifying the concept of organisational learning.

In both, the learning literature and the groupware literature, there have been legitimate complaints about a lack of prescriptions for applying normative academic theories. A further problem with organisational learning is that it is difficult to separate individual learning from its social context [30]. Therefore deconstructing learning into different levels is problematic. Much of the literature implies that learning is invariably an intentional process [20,21,23,24]. Huber [23] goes to the extent of claiming that organisational effectiveness must be improved in order for learning to occur. This is not realistic, as it neglects learning that takes place serendipitously which can be a vital source of learning and competitive advantage [15,25,31,32]. The following section will build on OL theory by demonstrating how, from a normative perspective, groupware facilitates OL.

\section{Groupware literature review}

Khoshafian and Buckiewicz [33] define groupware as

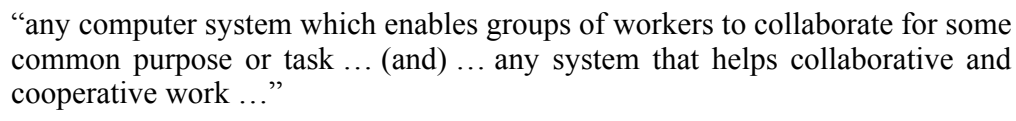

The Oxford Dictionary of Computing defines groupware as "software that supports the cooperation of a group of people, usually working in a distributed environment". Groupware can also be defined as "a set of tools to help groups work more effectively" [18, p.3]. Groupware is a very general concept that encompasses many different applications and technologies [33]. An example of a common groupware 
software package is Lotus Notes. Lotus Notes is a system for organising and distributing unstructured information [34]. Some common features on notes include bulletin boards, which enable users to interact and comment on issues in a structured format $[35,36]$; document sharing; news groups and e-mail [37]. E-mail is one of the most widely used groupware functions $[18,19,37]$. This feature enables a number of useful collaborative functions such as the ability to communicate in real-time, ability to send notes to predetermined groups and the ability to file communication in a structured form [37].

Other well-known groupware applications, are teleconferencing, video conferencing and e-mail conferencing, the latter of which is essentially an e-mail distribution list. Forums, another groupware function, allows for broadcasting of communications and dissemination of information at a group level [37]. It is usually some sort of shared file that allows access at different levels to different people. Some users may have permission to append and/or post information. The key benefit is that information can be broadcast without duplication [37]. Groupware functions enable one of the most important parts of organisational learning, which is the transfer of acquired knowledge from one part of an organisation to others [38]. According to Huber's [23] model, groupware enables the second phase, among others, of learning, which is information distribution.

Groupware applications allow individuals to codify communication and make it visible to the organisation. This reduces barriers to communication and facilitates sharing organisational knowledge [35]. Groupware technologies also facilitate the learning process by helping groups communicate and share work practices [39].

Groupware applications are relevant to learning in a sense that they are a means of connecting members of an organisation. This includes members from different units and members within a given unit. Huber [23] supports the use of groupware indirectly by pointing out that communication and knowledge sharing between units and within units is of paramount importance to organisational learning. In order for organisations to learn, there must be information to share and a means to share or disseminate information [23].

Groupware applications enable a great deal of organisational knowledge to be codified.

"If knowledge is power, then groupware empowers workers by providing an avenue for creativity, access to huge warehouses of information, and, most importantly, a means for collaboratively working with their peers." [33, p.10]

It has also been argued that communication and document routing functions in groupware can enable the same amount of work to be accomplished in less time, as measured by the number of meetings necessary to complete a task [40]. This can be seen as increasing learning efficiency, if it is assumed that knowledge is transferred in meetings. Huber [40] also posits that electronic bulletin board functions effectively disseminate information about the organisation's current problems, policies, and priorities. This permits managers to learn quickly, and use this knowledge to make better decisions. This, in turn, can lead to the desirable outcomes that many academics define as signs of learning [40]. While these claims sound encouraging, the author does not provide any empirical evidence to support them. Andeu and Ciborra [39] provide an example of a collaborative system implemented at Mrs Fields cookies. This system enables the head office to communicate routines and knowledge with stores. The learning benefit for the firm was the development and dissemination of core capabilities. Another key aspect of groupware is that people can work together who are located in different geographic regions. Groupware enables learning by facilitating shared work practices and communication 
within groups. Kock and McQueen [38] conducted research on how the e-mail conferencing (EC) features on Novell Groupwide were able to support knowledge dissemination in organisations. They showed that an electronic conferencing function can facilitate dissemination of knowledge between functional departments. For a full normative review of the potential of groupware to support learning, see Chauhan [41].

\section{Problems with groupware: a behavioural perspective}

Groupware has not been a flawless organisation learning solution. Even if the infrastructure and culture to share knowledge is in place, there is no guarantee that people will use it. The 'field of dreams' approach to groupware systems implementation - "if you build it, they will use it" - does not work unless there is a demonstrated need to intensively share information [19]. It is up to management to convey this need to all users. This is known as a push strategy.

Empirical research has shown that in some circumstances, users of groupware use substitute applications such as fax machines, corporate e-mail, telephones, private databases and the internet [17]. This is attributed to many factors including substitutes being better known, user friendly and robust. Ciborra [17] also notes that it is only in rare situations where an application is the only reasonable alternative available to accomplish a task, that a system will be used without question [17, p.8]. By examining a number of cases, Ciborra [17] found that it was rare for groupware to enable any sort of radical learning, such as double-loop learning [22]. Users often lack the resources (time, training, expertise) and incentives to share knowledge, and consequently to use groupware [17]. Ciborra goes on to argue that users often do not perceive the application (in this case, Lotus Notes) to be anything more than an e-mail program or database, rather than a group learning tool. Such factors result in groupware failures, which prevent organisations from gleaning the learning benefits from such applications.

Some applications require a large percentage of people to use the system. Critical mass of users is often a requirement to glean the full benefits from groupware $[36,42,47]$. Bowers [47] provides an example of a scheduling function that required the majority of people to use it, in order for it to function successfully. This situation seems to be that of a chicken and egg, in that you need everyone to use the function for it to work, yet people will not use the function unless it works. Other reasons why this particular groupware application did not achieve its full potential were a lack of perceived benefits from switching to the new work practices, reluctance to share documents, creation of extra work, undesired visibility of document processes, and cultural incompatibility [47]. Users were reluctant to try using new features, and with the exception of e-mail, the collaborative aspects of the system were a failure.

The IPM system at Unilever is a good example of how groupware applications, in this case Lotus Notes, do not effectively codify or externalise previously non-codified practices and knowledge. At Unilever, employees had problems searching for past product innovation information because finding it was contingent on development teams entering detailed reports, which were not always entered, and being able to identify to identify the correct words to search [35]. In some cases, employees may have legitimate reasons for not wanting knowledge to be codified and subsequently shared. This may be because they do not want to be evaluated based on their work-in-progress or because they 
feel their knowledge provides them with some sort of power. In such cases, employees have no reason to use the full functionality of groupware applications [17].

Some empirical work was conducted in a software development groupware at IBM, which found that there was a complete lack of awareness for the fact that a particular application even supported the work of groups [37]. Fallia [37] also found that some employees did not understand the full potential of what groupware applications could accomplish. In such cases, management has not done its job to make employees aware of the work tools available to them.

It is possible that the reason why organisations cannot glean the full benefits from various levels of learning is that the organisation may not be capable of using new generated knowledge. Bontis [6] provides the example of an individual undergoing training and building skills that cannot be applied in organisations. Conflict or frustration can exist because individuals, or groups, may desire to better themselves beyond what is necessary for achieving the organisation's objectives. In the same way, much of the knowledge that is disseminated and generated using groupware may not be beneficial. This indicates that groupware applications may be failing, not because they do not work, but because the knowledge they generate is not needed and as a result they are not used.

It has been established in a number of cases that groupware systems often impose ways of working on organisations [35]. Therefore, as opposed to these systems supporting existing processes, by facilitating learning, they end up imposing new processes. This brings about the question, of whether the potential improvements in learning come from the new system or the new processes imposed by the system. A further problem is that the person who puts in additional work to use the tool or update it, does not always gain from taking on additional work. Such situations are conducive to resistance of applications [19,36,37].

In practice, Lotus Notes, unless properly used, is merely a glorified e-mail program [34]. The same holds true for other groupware applications in that the benefits often cannot be gleaned unless they are implemented and used correctly.

\section{Hypothesis development}

This study seeks to gain a better understanding of the affects of push-pull implementation strategies on successful groupware usage. This is relevant to learning because any improvements in groupware usage will result in improvements in learning benefits. Drawing on Zmud's [43] argument, groupware applications that are introduced as a result of a need (pull) are more likely to succeed than those that are forced (push) onto the organisation. Success in this study is defined as providing an organisation with additional learning benefits (i.e., knowledge generation). The main hypothesis is reiterated as follows:

Hypothesis: Groupware applications that are need-pulled are more likely to succeed (provide learning benefits) than applications that are only technology-pushed. 


\section{Data collection}

Semi-structured interviews were used to conduct the research. This method was selected in an attempt to gain additional richness of findings beyond what would be possible with a structured survey, or interview. While fixed-open questions were set, the approach was flexible, leaving room for addition and omission of questions. The initial survey was pilot tested on several students to find areas where the clarity of the questions could be improved in order to alleviate problems with understanding the questions.

In addition to the interviews, manuals of the Teamlinks systems at InfoProv were reviewed. A number of the groupware functions on the systems including the scheduler, intranet, document manager and news functions were tested. In addition, a demonstration of the PMS at InfoProv was reviewed.

The research was conducted in the UK at a global information provider referred to as InfoProv. Four semi-structured interviews were conducted. The first two focused on Teamlinks, which is an organisation-wide groupware application similar to Lotus Notes. The latter two interviews focused on a PMS, which is a knowledge database that is being rolled out on a global scale. The interviews ranged in length from 40 minutes to 1 hour. The interviews were with a project coordinator, quality manager, user and project manager. The findings are arranged in two groups. The first includes information from the first two interviews, which dealt primarily with the Teamlinks applications. The second set of findings includes information from the latter two interviews, which dealt with the PMS.

\subsection{Findings: teamlinks application}

Teamlinks is InfoProv's e-mail and group collaboration application. Its features include a scheduler, directory and e-mail. Other groupware applications at the company users included video conferencing, teleconferencing, document flow functions, and a company intranet with collaborative features.

\subsubsection{Push findings}

These applications are pushed though the company's technical policy. This policy dictates the software that will be installed on new PCs. This is a more subtle push, in that it only dictates that the application is made available. Training is provided to introduce new employees to the groupware applications. This was backed up with a manual for Teamlinks and Calendar Manager.

The basic e-mail functions were widely used. So much so, that the second respondent, a quality manager, referred to them as 'institutionalized'. As a result of this, it was not necessary for management to push the e-mail function, because it was a necessary part of working for InfoProv. This shifted the duties of the technology push from the management level to lower levels. Employees knew that they needed to use e-mail in order to function in their teams.

Many of the functions on Teamlinks were not as widely used as e-mail. In the case of the scheduling function, calendar manager, management attempted to alleviate this problem by sending out electronic reminders to use functions that were not being used. The second respondent spoke of a number of cases he had experienced where his colleagues were not even aware of the basic functionality of the scheduling function. 
In particular, some people were not aware that they could access other people's schedules and make appointments with them and that they could specify the room that they would use for a meeting. Despite management's efforts, it was indicated that the application was still not used by some. This created problems because without the critical mass of users these functions cannot be properly used. The calendar manager functions were not used despite the fact that it is 'company standard' to use them.

\subsubsection{Pull findings}

The people interviewed did not have information on the perceived need for Teamlinks when it was first introduced, almost ten years ago. As one would expect, their knowledge was more in the area of current usage issues. This made it difficult to find out information on whether or not the application was implemented because of a need (pull) and/or because it was a new technology (push). This same problem was encountered when trying to examine the pull issues of several groupware cases studies.

There were a few methods that were available to examine employee's perceived need for groupware applications. One was whether or not they chose to adopt applications that were not absolutely necessary to use. An example was the choice not to use a scheduling function. However, it was not clear whether this lack of use was due to lack of awareness, know-how or need. In other cases, some groups of people opted to use substitute applications, such as Microsoft Outlook. This indicates that they saw a need for the generic function, a scheduler, but felt that another application could serve their purpose better.

\subsection{Findings: problem management system}

InfoProv is currently in the process of rolling out, on a global scale, a PMS. This system tracks problems and solutions for company software. It enables the product support team to efficiently codify solutions so they can be looked up to avoid having to solve the same problem twice. It also offers a structured, efficient method of storing problem records. Many of the records kept on the database are technical in their nature. Records include code and methods to assist with problems developing software. The first interview was conducted with a user of system and the second with a project manager who was responsible for rolling out the system in the Numeric Database Technology Group (NDTC).

\subsubsection{Push findings}

PMS is being rolled out with predominantly a push strategy. In fact, once the application is rolled out in each department, people will not have any substitute applications. They will effectively be forced to use PMS, assuming they will be using a problem management database.

A project manager was in charge of rolling out the system. The user mentioned that "it (the project manager) was a key element of driving the project". Another major push element of the implementation strategy was training and manuals that were provided to new users. 
PMS has the same problem as Teamlinks with critical mass. If all users are not on the same system, it creates more work in situations where the people not on the system need to be notified about a problem. Service Level Agreements, which dictate which applications should be used for communication, were set up to help support homogeneity in terms of application use.

The current implementation objective, in the NDTG, is to get the application installed on people's PC's. After this is accomplished the project manager will specify the precise methods and standards for using the application. He recognised that there would be some problems with getting people to use compatible configurations, but his present concern is getting the application rolled out. In the process of doing this, people are not sold on the full functionality of the new system, they are sold on the ease of switching to the new system from the old one.

\subsubsection{Pull findings}

Prior to using PMS, people would use Teamlinks to send development related problems to those who were thought to have answers. Management thought that this was inefficient and accordingly it was suggested that some sort of a PMS be implemented. It was introduced in a number of pilot sights and then decided that it would be implemented on a global scale.

The project manager mentioned that the NDTG was in favour of using the PMS because they liked the benefits. However, it was found that another group, the Development Group, did not see the benefits of using PMS and would have preferred to use an alternative system called Observation Reporter (OR).

\subsubsection{Secondary research}

Four cases from the groupware literature were also reviewed in an attempt to find evidence of push or pull strategies. Information was also collected on indications of the outcome of the systems. While some systems evidently had elements of a pull strategy, it was difficult to piece together the whole picture from cases that had not intentionally collected information on push-pull strategies. The findings are presented in Table 1.

Table 1 Case study analysis findings

\begin{tabular}{|c|c|c|c|}
\hline Caselapplication & $\begin{array}{l}\text { Evidence of 'push' } \\
\text { strategies }\end{array}$ & $\begin{array}{l}\text { Evidence of 'pull' } \\
\text { strategies }\end{array}$ & Outcome \\
\hline $\begin{array}{l}\text { Zeta } \\
\text { Orlikowski [19] } \\
\text { Incident Tracking } \\
\text { Support System }\end{array}$ & $\begin{array}{l}\text { Training } \\
\text { ITSS was accessible to } \\
\text { all members of the } \\
\text { customer service } \\
\text { department } \\
\text { Users had to use the } \\
\text { system to do their jobs } \\
\text { No substitutes }\end{array}$ & $\begin{array}{l}\text { Installed system } \\
\text { based on perceived } \\
\text { need to replace the } \\
\text { old system } \\
\text { Approved after a pilot } \\
\text { test to ensure it would } \\
\text { meet users needs }\end{array}$ & $\begin{array}{l}\text { Proactive } \\
\text { collaboration } \\
\text { amongst service } \\
\text { representatives } \\
\text { Learning benefits } \\
\text { from within each } \\
\text { division and within } \\
\text { different divisions }\end{array}$ \\
\hline
\end{tabular}


Table 1 Case study analysis findings (continued)

\begin{tabular}{|c|c|c|c|}
\hline Case/Application & $\begin{array}{l}\text { Evidence of 'push' } \\
\text { strategies }\end{array}$ & $\begin{array}{l}\text { Evidence of 'pull' } \\
\text { strategies }\end{array}$ & Outcome \\
\hline $\begin{array}{l}\text { World Bank } \\
\text { Bikson and } \\
\text { Eveland [46] } \\
\text { GroupSystem } \\
\text { Technology (group } \\
\text { decision support) }\end{array}$ & $\begin{array}{l}\text { System champion to } \\
\text { ensure successful } \\
\text { Implementation }\end{array}$ & $\begin{array}{l}\text { Assessment of users } \\
\text { needs by doing } \\
\text { research (primary and } \\
\text { secondary) }\end{array}$ & $\begin{array}{l}\text { Majority of users felt } \\
\text { the system } \\
\text { contributed to the } \\
\text { learning and } \\
\text { collaboration } \\
\text { objectives } \\
\text { System used by most } \\
\text { participants }\end{array}$ \\
\hline $\begin{array}{l}\text { Unilever } \\
\text { Ciborra and } \\
\text { Patriotta [35] } \\
\text { Lotus Notes based } \\
\text { Innovation process } \\
\text { management } \\
\text { system }\end{array}$ & $\begin{array}{l}\text { Employees required to } \\
\text { input all information } \\
\text { on the development of } \\
\text { a new products into the } \\
\text { IPM system } \\
\text { Desire to implement } \\
\text { the system quickly and } \\
\text { have fast visible } \\
\text { results. As a result the } \\
\text { system was pushed on } \\
\text { to people before they } \\
\text { really understood it } \\
\text { Technical training was } \\
\text { provided; but no } \\
\text { training was provided } \\
\text { on the organisational } \\
\text { implications }\end{array}$ & $\begin{array}{l}\text { Groupware in line } \\
\text { with info culture will } \\
\text { be pulled. } \\
\text { Used user feedback } \\
\text { about technical } \\
\text { aspects of the system } \\
\text { to improve technical } \\
\text { functionality }\end{array}$ & $\begin{array}{l}\text { Resistance: partially } \\
\text { attributed to } \\
\text { miss- match between } \\
\text { existing practices } \\
\text { and those dictated by } \\
\text { the structure of the } \\
\text { application } \\
\text { People did not like } \\
\text { having transparent } \\
\text { WIP } \\
\text { Duplication: } \\
\text { employees had to do } \\
\text { extra work to input } \\
\text { material into the } \\
\text { system (to meet } \\
\text { codification } \\
\text { requirements). }\end{array}$ \\
\hline $\begin{array}{l}I B M \\
\text { Failla [37] } \\
\text { Notes style, } \\
\text { video \& } \\
\text { teleconferencing }\end{array}$ & $\begin{array}{l}\text { Team achievement } \\
\text { award (indirect) } \\
\text { Other team-based } \\
\text { performance } \\
\text { compensation }\end{array}$ & $\begin{array}{l}\text { New matrix structure } \\
\text { increased the need for } \\
\text { coordination } \\
\text { Amalgamation of } \\
\text { products need for } \\
\text { group coordination }\end{array}$ & $\begin{array}{l}\text { Many applications } \\
\text { used but problems } \\
\text { emerged: (1) lack of } \\
\text { perceived benefits } \\
\text { (2) not aware } \\
\text { applications } \\
\text { supposed to support } \\
\text { teamwork (3) not } \\
\text { aware of potential }\end{array}$ \\
\hline
\end{tabular}

\section{Analysis}

This research assumes that if groupware applications were used successfully then learning would invariably occur. It should also be noted that even if groupware is implemented successfully learning does not always occur. Huber [22] argued persuasively that more organizational learning occurs when more of an organization's members obtain knowledge and recognize it as useful. Groupware undoubtedly can facilitate efficient dissemination of knowledge; however, it does not necessarily aid people in recognizing the use of new knowledge [41]. More emphasis on pull strategies could help alleviate this problem. If members recognize the need for an application, and 
the information it will provide, then it is likely that they will be more likely to recognize the information as useful, and learn from it.

The problem of the lack of utilisation of the full functionality of groupware also stems from people not recognising such applications as being beneficial or needed (lack of a pull strategy). This highlights the fact that new strategies are needed to help users recognise the benefits (need) of using groupware to facilitate learning. Users also need to recognise the importance of the knowledge they are gaining through groupware so that they take advantage of it by applying it, in some way, to help the business. Further exploration of push-pull strategies (and combinations of both) may to be useful in improving the current situation.

The findings indicate that push strategies are more prevalent than pull strategies. However, this is not to say that pull strategies are not as prevalent. This could be the case, but it appears that they are more difficult to research as the people who would be aware of pull strategies are those who initially implement a system. In the research push strategies were more prevalent both the empirical work and the review of cases (see Table 1). While the results indicate that more emphasis on pull strategies could improve groupware success, they are in no way representative or conclusive.

\subsection{Push issues}

The results indicate that there is no shortage of push tactics in the implementation of groupware applications. A push technique that which often comes up in the literature, is that of providing users with incentives to use a system [17-19,44]. An example of incentives facilitating the successful use of a system can be found in Ackerman's [44] Answer Garden case, where contributors and users of the system were able to reduce their workload by using the system. It was found that applications and features that provided users with a perceived benefit were more successful. For example, e-mail was perceived to be easy to use, efficient and widely used, while the scheduling function on teamlinks was perceived to be difficult to use and it was not widely accepted. E-mail was established to the point that it became 'institutionalized'. As Crossan et al. [4] pointed out, organisations can institutionalise knowledge or practices that become of part of the organisation, as opposed to only be embedded within individuals. This seems to be the case with the e-mail function on Teamlinks, at InfoProv. What is interesting is that it is difficult to separate the push from the pull. For example, when the Teamlinks system was initially implemented there people must have had some good reasons for using (pulling) the e-mail function. Some of these would have likely been faster communication and efficient distribution of documents. However, it seems that after the e-mail function was 'institutionalized', using the e-mail function became necessary because of the large of percentage of people that depended on electronic communication. As a result, people came to depend on using e-mail. This was confirmed by Neilson [18] who noted that peer pressure is a motivating factor for using groupware systems. This shows how a pull strategy or reason for use can easily turn into a push strategy.

A push technique that is commonly advocated in groupware literature is support from top management [42]. However, management support is a necessary, but not sufficient, condition for application success [42]. InfoProv's project managers were perceived to play an important role in successfully implementing the PMS. However, the project manager does not always have the long term best interests of the organisation in mind. The findings indicated that the project manager at InfoProv was making compromises in 
order to get the PMS rolled out. An example of this was the fact that the manager did not worry about how people would actually use the function - he was initially only concerned with getting the application rolled out. Again, this indicates a lack of balance between push-pull strategies. In this case, there was too much focus on the push, which could be detrimental to the success of the application. In other words, the need to roll out the application quickly (technology push) should be balanced with the immediate and long-term needs of the users. It is possible that if these needs are not taken into consideration, the application will not be used, as was the case with the scheduling function that Bowers [47] describes. In the case of PMS at InfoProv, the project manager is going to wait until after the implementation to find a way to coordinate people's different tastes in terms of settings on the PMS. If no agreement is reached in terms of the settings, it could lead to the failure of the PMS. A little more emphasis on user needs (pull strategies) could alleviate such a problem.

It has been noted in the literature [46] that push techniques can increase groupware implementation success. A standard push technique that was found in most of the literature and cases was training. Bikson and Eveland [46, p.161] noted that training was viewed by the implementation team at the World Bank as being "a critical factor in deploying the technology successfully". Orlikowski [19], Grudin [36] and Neilson [18] have also advocated the use of training to increase the success of groupware applications. Neilson goes on to explain how training leads to a perceived ease-of-use of collaborative applications, which contributes to user satisfaction.

Despite the strong presence of push strategies, groupware was found to be far from flawless. This was shown in the literature (see Table 1) and with the Teamlinks systems at InfoProv. Despite the presence of extensive push strategies to implement the Teamlinks package, most of the functionality was not used. The fact that critical mass was not achieved with the calendar manager, the scheduling function, is evidence that the training, manuals, e-mail reminders and company standards, were not enough to ensure functions were used. The missing link in the case of the scheduling function could have been the lack of a pull strategy. It is possible that the lack of user support for the need to schedule electronically is a stronger force than all the push elements combined. There was a similar situation with the PMS. It had an extensive push strategy, but there was no evidence of a pull. The same push elements were used, training, project management, manuals etc. Yet the full functionality of PMS was not utilised. This indicates that a push is simply not enough to insure the success of an application. Zumd's [43] theory states that technology implementation-success can be maximised by combining push and pull strategies. If this is, true then InfoProv can improve its success by being more aware of pull strategies of implementation.

\subsection{Pull issues}

Pull strategies have been around for as long as information systems. In fact, the whole point of implementing an information system is often to meet a need. One of the techniques that is used to understand a social context, and therefore user needs, is ethnography [47]. However, a need-pull is difficult to define, because management can recognise a need for a new groupware system, but if users do not recognise the need, it makes the existence of a pull strategy difficult to confirm. 
The fact that all the people interviewed at InfoProv did not have any idea about the perceived need for PMS when it was first introduced, may be an indication that there was not much emphasis put on pull strategies. Even if the application was introduced as a result of a need, it would still show a lack of pull tactics for current users not to have any idea of the reason (need) for the system to be implemented. This seemed to be the case with InfoProv.

There was one way in which to evaluate people's perceived need for software. This was by examining the use of particular functions. Although this is not the traditional way of examining pull strategies, it can provide some indication of functions and applications that users perceive a need for. In the case of InfoProv, users perceived a need for a scheduler but did not always agree on which application should be used to fill this need (Teamlinks, Outlook etc.). This indicates that the generic need (or pull) may have been present at the time of deciding to introduce Teamlinks. This could explain the application's success in terms of user acceptance of e-mail for the scheduling functions.

Evidence was found that supports the notion that pull strategies did exist in the implementation of the PMS. The fact that management decided to implement the PMS, after deciding that using Teamlinks to perform the same function was inefficient, was an indication that the application was pulled. In addition, the fact that the Numeric Database Technology Group favoured the application because of its benefits is also an indicator of this. The fact that the application has already been successful in the technical support department indicates that there was a perceived need for the technology.

\subsection{Additional analysis}

All of the cases (see Table 1) analysed seemed to have push and pull elements present in their implementation strategy. The first two cases had strong push and pull strategies and were both considered successful in that the systems were used and learning benefits were perceived to be gained. The second two cases analysed seemed to be marginally successful in that they were used, but the full functionality was not utilised in the latter case. It is interesting to note the first two cases had proper pull strategies, meaning the needs of the organisation were properly assessed prior to implementing the system. In the second two cases, needs were only assessed after the implementation to find ways of improving the system in the case of Unilever. This may indicate that systems with pull strategies, in addition to the existing push, are more likely to succeed in terms of user acceptance and perceived learning benefits.

Additional literature supports the argument that the presence of pull strategies can improve the success of groupware applications. Bontis [6] found that information that can not be used does not benefit an organisation. If a groupware system is properly assessed using a pull strategy (meaning it can meet user's needs) then it is more likely that the information that the system will disseminate will also meet users' needs. If this is the case, then groupware systems that are pulled are more likely to disseminate information that can be used, and therefore provide learning benefits. Fiol and Lyles [20] pointed out that information overload can be a hindrance to OL. Again, if a proper pull strategy was implemented which assessed the needs of the organisation, it would rule out implementing any systems that would overload users, and hinder learning. Therefore, according to Fiol and Lyles, theory of information overload groupware implementation-success-rates could be improved by utilising pull strategies. 
Grudin [36] has pointed out that one of the problems with groupware is that support has focused in the organisational and individual levels. In the cases analysed and at InfoProv, it seemed that most of the need assessment took place at the individual level. Possibly, pull strategies could be improved if they looked at the needs of the group level, which would be the most appropriate for collaborative applications.

It should be noted that while this research did indicate that there is a lack of presence of pull strategies, it did not indicate why this is the case. It is not necessarily the case that pull strategies did not exist at InfoProv and in the cases examined. It is possible that pull strategies were present at the time of the conception of the idea of the system, but new managers that take on the responsibility of the system may not be aware of these. It is also possible that pull strategies never existed in the first place. It is believed that both these cases could hinder the potential success of a groupware system. In the former case, managers who implement systems that they do not understand the need for, may have problems convincing people of the relevance of such a system. This could lead to user resistance. In cases where pull strategies are not used, management is taking a gamble by implementing a system that may not be needed.

\subsection{Realisation that push and pull cannot be separated}

From primary research and review of groupware implementation cases, it is believed that push and pull strategies are far from mutually exclusive. On the contrary, elements of both seem to be pervasive in most cases. It is unlikely that any system would succeed as a result of only one type of implementation tactic. Orlikowski's [19] indirectly argues this by putting forward a theory of emergent change. Emergent changes come about over time, and are ongoing, which implies they rely on needs to be seen as changing [19]. Therefore new applications will be needed to meet user's changing needs. Also, changes are not always instantaneous, as oppose to the theory of punctuated equilibrium, which implies that push tactics cannot insure the immediate success of a new application [19]. Buchanan [42] noted that it is not just top-down management support and other push techniques that lead to successful groupware applications. It is also necessary to have bottom up user support, which comes from having the correct pull tactics to support groupware implementation. This view is in line with Smud's [43] belief that success of technological innovation implementations can be improved by having both types of strategies. The analysis of the cases also indicates that this is true.

\subsection{Prescriptions}

There have been some guidelines provided in the literature for improving the prospects of groupware implementations. An example is Munkvold [45] who advises management to create incentives, provide guidelines for using the system and provide training for using the system. It should be noted that these guidelines include both push and pull strategies. The former two are pull strategies and the latter a push. The fact that Munkvold [45] has emphasised pull over push strategies for improved implementation of groupware may indicate that the lack of success is a result of a lack of emphasis on pull strategies.

The intention of this analysis of push-pull strategies was not to nullify existing strategies of improving groupware implementations, such as those provided by Neilson [18]; on the contrary, it aims to complement those strategies by providing an additional tool to aid in the implementation process. 
Findings indicate that there is a lack of presence and awareness of pull strategies and that this may be causing groupware applications to fail. These findings need to be confirmed by further research, which will be outlined in the conclusion.

\section{Conclusion}

The objective of this paper is to contribute to the disciplines of organisational learning and information systems by examining a possible way to improve groupware implementations, which could lead organisations to additional learning benefits.

Groupware's failure to provide full learning benefits is a result of a mismatch between the technology and the organisational context [35]. It may be possible to alleviate this problem by doing a better job of matching the technology to the existing context. This may be achieved by incorporating both push and pull tactics of implementation. In particular, pull tactics can be used to properly assess the needs and constraints of the existing organisational context, and by doing so, provide a rich picture that can guide the selection or development of the according groupware application. By taking such steps, practitioners could improve the success rate of groupware application implementations.

Organisational learning field is best researched via case study methods because it is necessary to look at multiple levels of analysis and gain a holistic perspective. Further research done in this area should consider the case study approach as it would provide the depth and richness that is needed to better understand the social context in which groupware is implemented, and learning takes place.

Organisations have different needs in respect to groupware systems. However, the push-pull framework applied does not fully recognise the role of radical change. The idea of assessing the needs of an organisation (a pull strategy) and implementing the appropriate technology assumes that the needs that are assessed will remain constant for a fixed period of time. On the contrary, in today's rapidly changing environment, needs are likely to change constantly. Therefore the assumption of constant needs which the push-pull framework makes should be made explicit in any further research in this area. Furthermore, the results found at one organisation cannot easily be generalised. In other words, the findings are not statistically significant and accordingly quantitative research, possibly in the form of a Likert-type survey, should be conducted to test whether or not the findings apply to a statistically significant number of organisations.

By no means was the execution of the primary research flawless. Many difficulties were encountered along the way. For one, it was difficult to secure meetings with the correct respondents at InfoProv. In retrospect it would have been better to interview a project manager who was involved with the decision to initially implement PMS. This would have provided more insight into the initial pull strategy. In addition, it was difficult to glean the correct information from respondents, even after interviews were secured. The main problem was keeping interviewers on track.

After reviewing the organisational learning literature, it became evident that most of the literature is concerned with the acquisition of knowledge. Not enough attention has been paid to the dissemination of knowledge, which is a function which groupware supports [18,25]. Accordingly, additional research is needed in this area to better understand groupware's role in this function and how it can be improved. As Ciborra [17] has pointed out, looking at the learning processes around the application could provide 
some insight into the dynamics between groupware and the surrounding organisation. This is an area that requires further exploration.

Successful implementation of groupware is not enough to guarantee full learning benefits. As Nonaka's [28] theory of order from chaos implies it is necessary to ensure that the system is continually fed with new up-to-date information to disseminate throughout the organisation. There seems to be a gap in the literature in respect to looking at the quality of information input into groupware systems. This area is relevant for further research for the simple reason that if junk-information is put into groupware systems, then junk-knowledge will be the output. As discussed in the analysis, this area can be researched by looking at how pull strategies can be used to alleviate this problem.

More research is needed to explore the effects of using push-pull strategies to improve groupware implementation projects' success. In particular, in-depth case studies and quantitative research should be conducted to test whether or not more emphasis on pull strategies will help improve the success rate of groupware systems.

It would also be useful to determine whether or not a formalised incentive plan alters participation and usage rages in various groupware systems. For example, Knexa Solutions (see www.Knexa.com) offers a unique groupware system that provides incentives in the form of ICUs (intellectual capital units) or electronic tokens that are accumulated by users for various knowledge sharing behaviours (i.e., answering questions, editing reports). At the end of a specific period of time, users then redeem their ICUs based on a pre-determined redemption schedule (e.g., 500 ICUs $=$ Palm Pilot or 5000 ICUs $=5$ extra vacation days). This process provides users with an incentive to use the system.

Within the area of pull implementation strategies, it would be helpful for researchers to identify whether the problem is a lack of pull implementation strategies or a lack of awareness and communication of them. Once the problem has been established, academics and practitioners alike can work on finding some prescriptions to deal with the problem of unsuccessful groupware implementation and the resulting unfulfilled learning potential. Further research in this area may help organisations learn more effectively, which will become increasingly important in today's rapidly changing competitive environment.

\section{References}

1 Bontis, N. (1999) Managing an Organizational Learning System by Aligning Stocks and Flows of Knowledge: An Empirical Examination of Intellectual Capital, Knowledge Management and Business Performance, PhD dissertation, Ivey School of Business, University of Western Ontario, London, Canada.

2 Bontis, N., Crossan, M. and Hulland, J. (2002) 'Managing an organizational learning system by aligning stocks and flows', Journal of Management Studies, Vol. 39, No. 4, pp.437-469.

3 Crossan, M., Lane, H. and White, R. (1999) 'An organizational learning framework: from intuition to institution', Academy of Management Review, Vol. 24, No. 3, pp.522-537.

4 Crossan, M., Lane, W., White, R. and Djurfedt, L. (1995) 'Organizational learning: dimensions for a theory', International Journal of Organizational Analysis, Vol. 3, No. 4, pp.337-360.

5 Mumford, A. (1992) 'Individual and organizational learning: the pursuit of change', Management Decisions, Vol. 30, No. 6, pp.143-148. 
6 Bontis, N. (1999) 'Managing organizational knowledge by diagnosing intellectual capital: framing and advancing the state of the field', International Journal of Technology Management, Vol. 18, Nos. 5-8, pp.433-462.

7 Bontis, N. (2001) 'Assessing knowledge assets: a review of the models used to measure intellectual capital', International Journal of Management Reviews, Vol. 3, No. 1, pp.41-60.

8 Bontis, N. (2002) World Congress of Intellectual Capital Readings, Butterworth Heinemann KMCI Press, Boston.

9 Bontis, N., Dragonetti, N., Jacobsen, K. and Roos, G. (1999) 'The knowledge toolbox: a review of the tools available to measure and manage intangible resources', European Management Journal, Vol. 17, No. 4, pp.391-402.

10 Bontis, N., Chua, W. and Richardson, S. (2000) 'Intellectual capital and the nature of business in Malaysia', Journal of Intellectual Capital, Vol. 1, No. 1, pp.85-100.

11 Choo, C. and Bontis, N. (2002) The Strategic Management of Intellectual Capital and Organizational Knowledge, Oxford University Press, New York.

12 Stewart, T. (1997) Intellectual Capital: The New Wealth of Organizations, Currency Doubleday, New York.

13 Bontis, N. and Fitz-enz, J. (2002) 'Intellectual capital ROI: a causal map of human capital antecedents and consequents', Journal of Intellectual Capital, Vol. 3, No. 3, pp.223-247.

14 Edvinsson, L. (2002) Corporate Longitude, Bookhouse, Stockholm.

15 Nonaka, I. (1991) 'The knowledge-creating company', Harvard Business Review, November-December, pp.96-104.

16 Venkatraman, N. (1991) 'IT-induced business reconfiguarion', in Morton, S. (Ed.): Corporation of the 1990's: IT and Organizational Transformation, John Wiley and Sons, New York.

17 Cibbora, C. (1996) Groupware and Teamwork: Invisible Aid or Technical Hindrance? John Wiley and Sons, Chichester.

18 Neilson, R. (1997) Collaborative Technologies and Organizational Learning, Idea Publishing Group, London.

19 Orlikowski, W. (1996) 'Improvising organizational transformation over time: a situated change perspective', Information Systems Research, Vol. 7, No. 1, pp.23-59.

20 Fiol, C. and Lyles, M. (1985) 'Organizational learning', Academy of Management Review, Vol. 10, No. 4, pp.803-813.

21 Garvin, D. (1993) 'Building a learning organization', Harvard Business Review, Vol. 71, No. 4, pp.78-96.

22 Argyris, C. (1999) On Organizational Learning, Blackwell Press, Cambridge.

23 Huber, G. (1991) 'Organizational learning: the contributing processes and literatures', Organizational Science, Vol. 2, No. 1, pp.88-115.

24 Cangelosi, V. and Dill, W. (1965) 'Organizational learning: observations toward a theory', Administrative Sciences Quarterly, Vol. 10, pp.175-203.

25 Nevis, E., Dibella, A. and Gould, J. (1995) 'Understanding organizations as learning systems', Sloan Management Review, Winter, pp.73-85.

26 Miller, D. (1996) 'A preliminary typology of organizational learning: synthesizing the literature', Journal of Management, Vol. 22, No. 3, pp.485-504.

27 Bontis, N. (1996) 'There's a price on your head: managing intellectual capital strategically', Business Quarterly, Summer, pp.40-47.

28 Nonaka, I. (1988) 'Creating organizational order out of chaos', California Management Review, Vol. 30, Spring, pp.57-73.

29 Simon, H. (1991) 'Bounded rationality and organizational learning', Organizational Science, Vol. 2, No. 1, pp.125-134. 
30 Magalhaes, R. (1998) 'Organizational knowledge and learning in knowing in firms', in Krogh, G., Roos, J. and Kleine, D. (Eds.): Knowing in Organizations, Sage, London.

31 Ciborra, C. (1993) Teams, Markets and Systems, Cambridge University Press, Cambridge.

32 Mintzberg, H., Ahlstand, B. and Lapel, J. (1998) Strategy Safari: A Guided Tour Through the Wilds of Strategic Management, The Free Press, New York.

33 Khoshafian, S. and Buckiewicz, W. (1995) Introduction to Groupware, Workflow, and Workgroup Computing, John Wiley Publishing, Toronto.

34 Alsop, S. (1997) 'Lotus notes is a software fantasy', Fortune, Vol. 135, No. 4, pp.183,184.

35 Ciborra, C. and Patriotta, G. (1996) 'Groupware and teamwork in new product development: the case of a consumer goods multinational', in Cibbora, C. (Ed.): Groupware and Teamwork: Invisible Aid or Technical Hindrance?, John Wiley and Sons, Chichester.

36 Grudin, J. (1994) 'Groupware and social dynamics: eight challenges for developers', Communications of the ACM, Vol. 37, No. 1, pp.92-105.

37 Failla, A. (1996) 'Technologies for co-ordination in a software factory', in Ciborra, C. (Ed.): Groupware and Teamwork: Invisible Aid or Technical Hindrance?, John Wiley and Sons, Chichester.

38 Kock, N. and Mcqueen, R. (1998) 'Groupware support as a moderator of interdepartmental knowledge communication in process improvement groups. An action orientated study', Information Systems Journal, Vol. 8, No. 3, pp.183-198.

39 Andreu, R. and Ciborra, C. (1998) 'Organizational learning and core capabilities development: the role of information technology', in Galliers, R. and Baets, W. (Eds.): Information Technology and Organizational Transformation, John Wiley and Sons, Chichester.

40 Huber, G. (1990) 'A theory of the effects of advanced information technologies on organizational design, intelligence, and decision making', Academy Management Review, Vol. 15, No. 1, pp.47-71.

41 Chauhan, N. (1998) Organizational Learning and Groupware Technologies, Working Paper, London School of Economics, Department of Information Systems.

42 Buchanan, B. (1998) Consequences of Groupware Use: An Organizational Issue Based Perspective, Working Paper, London School of Economics, Department of Information Systems.

43 Zmud, R. (1984) 'An examination of push-pull theory applied to process innovation in knowledge work', Management Science, Vol. 30, No. 6, pp.727-738.

44 Ackerman, M. (1990) Answer Garden: A tool for growing organizational memory, Center for Information Systems Research MIT, Cambridge, Massachusetts.

45 Munkvold, B. (1998) Challenges of IT Implementation for Supporting Collaboration in Distributed Organizations, Working Paper, Department of Information System, Agder College, Norway.

46 Bikson, T. and Eveland, J. (1996) 'Groupware implementation: reinvention in the sociotechnical frame', Proceedings CSCW 96, Association for Computing Machinery, pp.428-437.

47 Bowers, J. (1995) 'Making it work: a field study of a CSCW network', The Information Society, Vol. 11, No. 3, pp.189-207. 